\title{
Diagnóstico diferencial del raquitismo hipocalcémico. Caso clínico
}

\author{
ANA ROCHA R. ${ }^{1,2}$ \\ 1. Unidad Endocrinología, Hospital Padre Hurtado. \\ 2. Unidad de Endocrinología Infantil, Clínica Alemana de Santiago.
}

\begin{abstract}
\section{Differential diagnosis in hypocalcemic rickets. A clinical case}

Introduction: Hypocalcemia is rare in patients attending pediatric emergency services. Rickets can present as a chronic hypocalcemia often asymptomatic, poor growth rate, psychomotor delay and bone abnormalities, but some patients may present tetanic seizures. Although its incidence has decreased, a resurgence of rickets has been described. Objective: To present a case of a child with hypocalcemic rickets, whose diagnosis was delayed. Case report: Preschool of 2,4 years old with gait disturbance, poor growth rate, muscle spams and signs of active rickets. Laboratory results showed hypocalcemia, normophosphemia, alkaline phosphatase, high PTH and normal 25-hydroxyvitamin D levels. She received treatment with calcium and calcitriol and had a good response; Vitamin D dependent rickets type I was diagnosed. Conclusion: Classics signs and symptoms of rickets, as hypocalcemic manifestations, should lead us today to diagnose rickets. Better knowledge of this disease will avoid retarded diagnosis and give a suitable treatment.
\end{abstract}

(Key words: Rickets, hypocalcemia, calcitriol-deficiency.)

Rev Chil Pediatr 2013; 84 (6): 672-680

\section{RESUMEN}

Introducción: La hipocalcemia es un hallazgo infrecuente en los pacientes atendidos en los servicios de urgencia pediátricos. El raquitismo se puede presentar como una hipocalcemia crónica la mayoría de las veces asintomática, sin embargo, algunos pacientes presentan tetanias hipocalcémica. Objetivo: Presentar el caso clínico de una niña con raquitismo hipocalcémico, cuyo diagnóstico fue tardío. Caso clínico: Prescolar de 2 años 5 meses con alteración en la marcha, mal incremento ponderal, espasmos musculares y signos de raquitismo activo. Los exámenes revelaron hipocalcemia severa, normofosfemia, fosfatasa alcalina y PTH elevada y niveles normales de 25 hidroxivitamina D. Se manejó con calcio y calcitriol, y se diagnosticó raquitismo

Recibido el 22 de octubre de 2013, aceptado para publicación el 26 de noviembre de 2013.

Este trabajo cumple con los requisitos sobre consentimiento /asentimiento informado, comité de ética, financiamiento, estudios animales y sobre la ausencia de conflictos de intereses según corresponda.

Correspondencia a:

Dra. Ana Rocha R.

arochar@alemana.cl 
vitamina D dependiente tipo I. Conclusión: Los síntomas y signos clásicos de raquitismo, así como la hipocalcemia, deben hacernos plantear hoy en día el diagnóstico de raquitismo. Un mejor conocimiento de esta patología permitirá evitar el retraso en el diagnóstico y un tratamiento más oportuno.

(Palabras clave: Raquitismo, hipocalcemia, deficiencia calcitriol).

Rev Chil Pediatr 2013; 84 (6): 672-680

\section{Introducción}

La hipocalcemia grave puede manifestarse con temblores, debilidad muscular, tetania y laringoespasmo entre otros. Su detección reviste especial importancia, dado que los pacientes sintomáticos constituyen una emergencia endocrinológica que precisa de corrección intravenosa de la calcemia en forma inmediata ${ }^{1,2}$.

Dentro de las causas de hipocalcemia está el raquitismo. El raquitismo es la afección ósea resultante de la deficiente mineralización del hueso o del tejido osteoide en crecimiento; se puede manifestar como una hipocalcemia crónica, la mayoría de las veces asintomática, mal incremento pondoestatural, retraso del desarrollo psicomotor y alteraciones óseas como cráneo tabes, rosario costal, surco de Harrison, ensanchamiento metafisario y genu valgo o varo, sin embargo algunos pacientes puede presentar tetania hipocalcémica ${ }^{3}$.

El raquitismo deriva de diferentes desórdenes, como carencia de vitamina $\mathrm{D}$, síndromes de malabsorción intestinal, enfermedad renal crónica, hipofosfatasia y raquitismo de origen genéticos, dentro de los cuales están los hipofosfémicos y aquellos vitamina $\mathrm{D}$ dependien$\mathrm{te}^{4}$.

El objetivo de esta comunicación es presentar un caso clínico de raquitismo hipocalcémico, que presentó espasmos musculares por tetania, retardo del crecimiento y alteraciones óseas.

\section{Caso clínico}

Preescolar de 2 años y 5 meses de sexo femenino, de estrato socioeconómico medio bajo. Hija de padres sanos no consanguíneos, madre 40 años (talla $155 \mathrm{~cm}$ ), padre 50 años (talla $172 \mathrm{~cm}$ ), hermano de 4 meses sano, dos medio hermanos paternos de 13 y 20 años sanos y una media hermana materna de 15 años, sana.

Producto de un segundo embarazo, sin complicaciones, nació por parto vaginal a las 39 semanas, pesó $3.750 \mathrm{~g}$, midió $49 \mathrm{~cm}$, perímetro craneano $35 \mathrm{~cm}$, Apgar 9-10. Recibió lactancia materna exclusiva hasta los 3 meses, luego leche maternizada, incorporando sólidos desde los 6 meses. Actualmente recibe leche entera $500 \mathrm{ml}$ al día y 2 comidas con 2 postres. Recibió vitamina ACD durante el primer mes, exposición solar en verano y esporádica en invierno.

Caminó a los 18 meses con dificultad y caídas frecuentes, tenía una motricidad fina normal y retraso de lenguaje.

$\mathrm{Su}$ crecimiento pondoestatural se observa en la figura 1A y 1B: a los 8 meses peso $10,9 \mathrm{~kg}$ (P/E p99, 2,48 DS) y longitud $68,5 \mathrm{~cm}$ (T/E p40,8, -0,23 DS), (curvas OMS), a los 16 meses su peso era $11,2 \mathrm{~kg}(\mathrm{P} / \mathrm{E} \mathrm{p} 85,0,56 \mathrm{DS})$ y longitud $76 \mathrm{~cm}$ (T/E p17, -0,96DS); a partir de entonces presenta una disminución progresiva de velocidad de crecimiento. A los 18 meses inició control en traumatología por genu varo, alteración en la marcha e incurvación de miembros inferiores.

A los 19 meses fue atendida en el servicio de urgencia por presentar repetidos movimientos clónicos de extremidades sin fiebre, manejadas como crisis convulsivas parciales e interpretadas posteriormente como tetania.

En el estudio radiológico esquelético solicitado por traumatología, se encontraron signos compatibles con raquitismo, incluyendo osteopenia generalizada, irregularidades en copa de las metáfisis (figura 2); por lo que fue derivada a Endocrinología Infantil. 


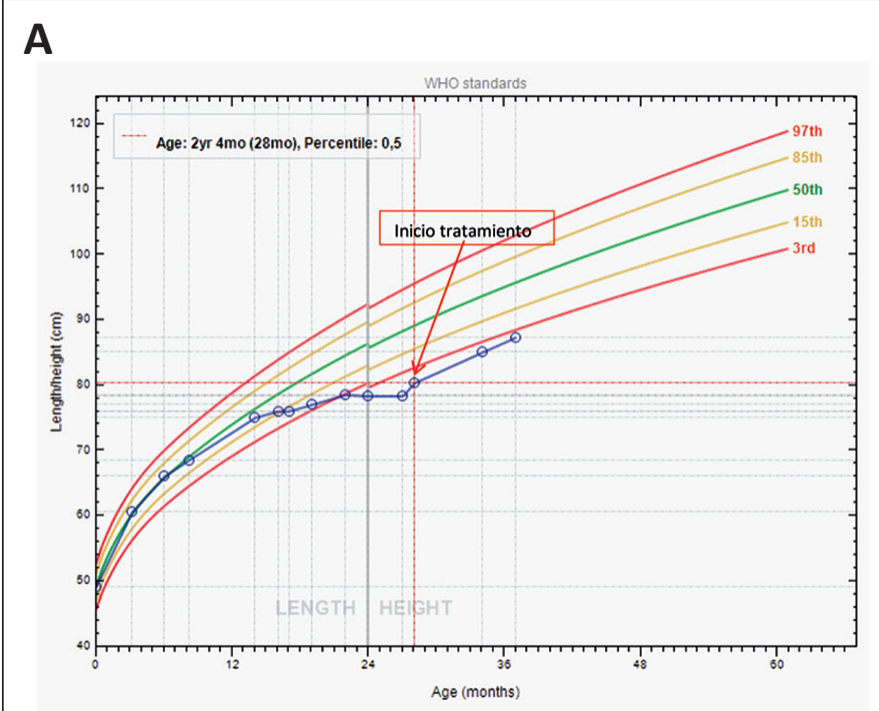

B

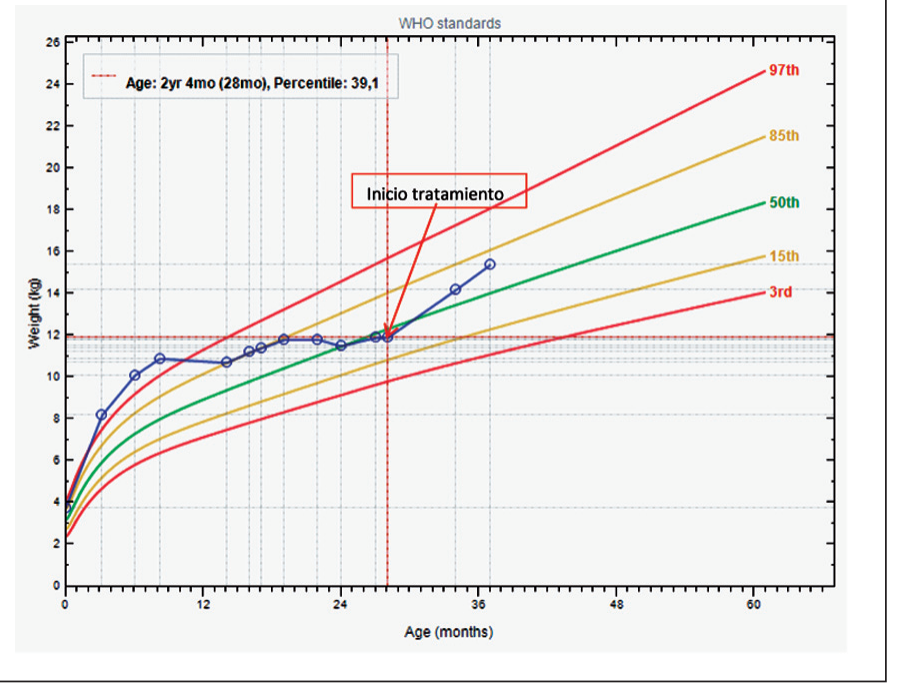

Figura 1. Evolución antropométrica. A: talla/ edad. B: peso/edad.
A los 2 años y 4 meses consultó en endocrinología infantil, destacando al examen físico, peso 11,9 kg (P/E p39, -0,28 DS), longitud $81 \mathrm{~cm}(\mathrm{~T} / \mathrm{E} \mathrm{p} 0,5,-2,58 \mathrm{DS})$, buen estado general, piel y mucosas sanas, dentición normal. A nivel osteoarticular, en el examen clínico, se encontró engrosamiento metafisario, signos de Chvostek (+), rosario costal, surco de Harrison, arqueamiento de las tibias, leve genu varo, hipotonía generalizada, abdomen prominente e inestabilidad en la marcha (figura 3 ).
Se solicitaron exámenes que revelaron hipocalcemia severa de 5,6 mg/dl, fosfemia normal $(4,9 \mathrm{mg} / \mathrm{dl})$, fosfatasas alcalinas elevadas de 1.614 (valor normal (VN) para la edad $<600$ ), paratohormona (PTH) de $304 \mathrm{pg} / \mathrm{ml}$ (VN: 9-52) y $25 \mathrm{OH}$ Vitamina D de $37,4 \mathrm{ng} /$ ml (VN: > 35). Otros exámenes solicitados fueron: gases venosos normales, creatininemia de $0,49 \mathrm{ng} / \mathrm{ml}$, función hepática normal, anticuerpos antitrasglutaminasa negativos y $\operatorname{IgA}$ normal. 

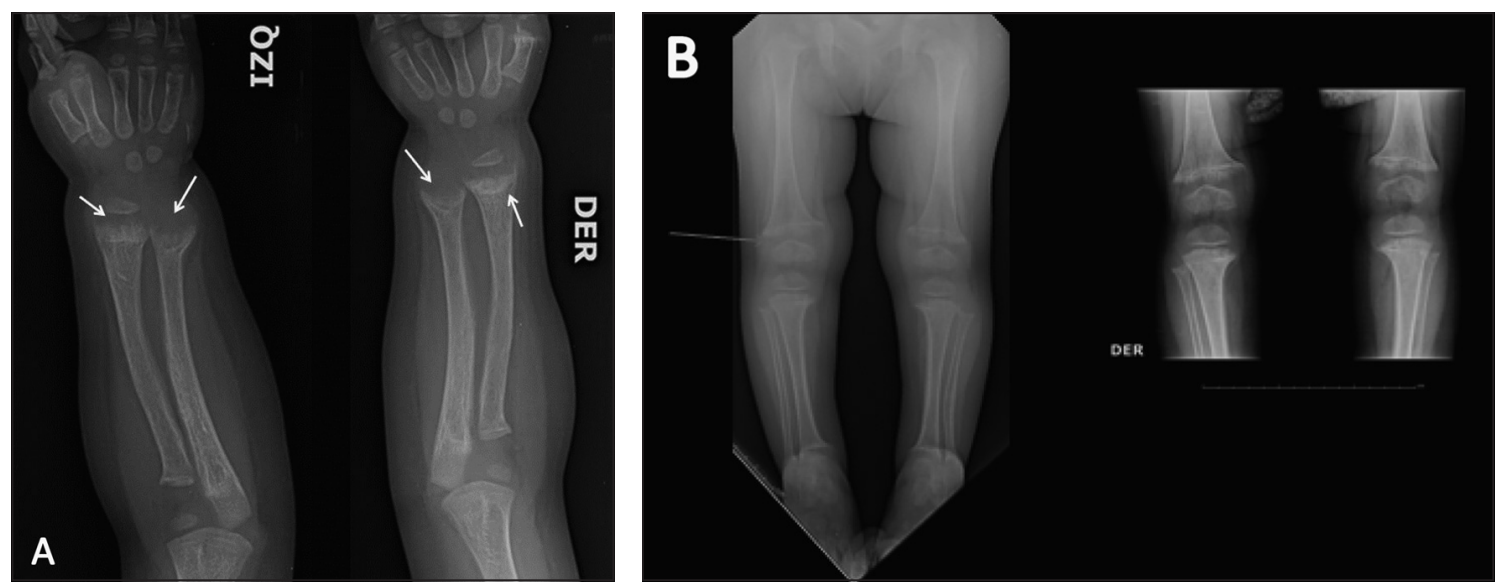

Figura 2. Radiografía AP de ambos antebrazos (A) y rodillas (B) muestran osteopenia difusa y marcada irregularidad de las metáfisis distales de ambos radios y cúbitos (flechas), con ensanchamiento secundario de las fisis o placas de crecimiento, hallazgos característicos de raquitismo.

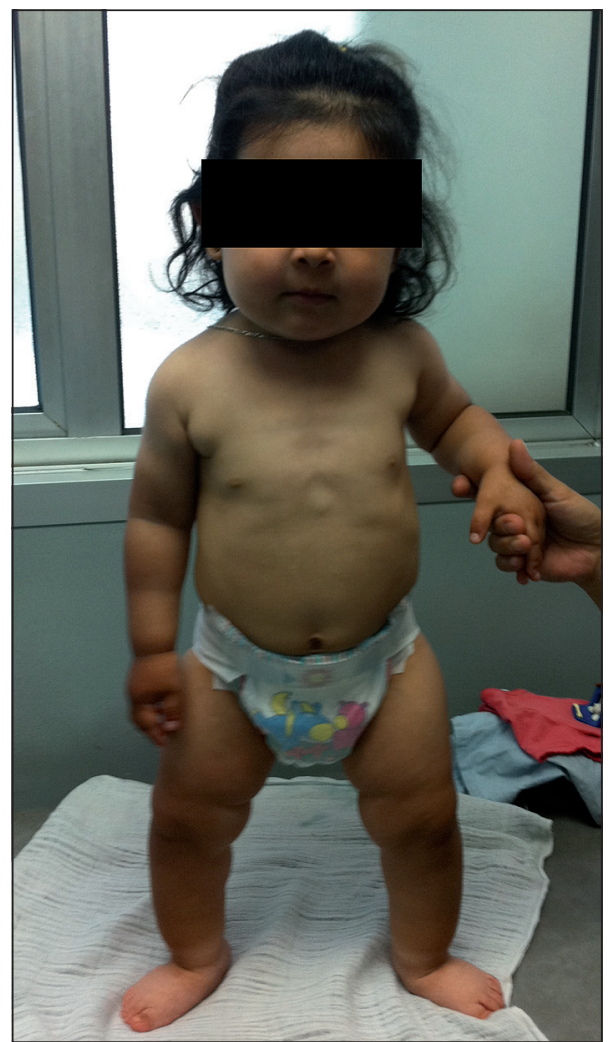

Figura 3. Fotografía de la paciente a los 2 años 5 meses que consulta en endocrinología infantil. Muestra a nivel osteoarticular engrosamiento metafisario, rosario costal, surco de Harrison y abdomen prominente. Extremidades inferiores muestran arqueamiento de las tibias y leve genu varo.
El cuadro clínico era compatible con un diagnóstico de raquitismo hipocalcémico, por lo que se hospitalizó para corrección intravenosa de calcio, inicialmente recibió 3 bolos de gluconato de calcio $10 \% 2 \mathrm{ml} / \mathrm{kg} /$ dosis, luego se inició infusión continua de calcio $10 \mathrm{ml} /$ $\mathrm{kg} / 24 \mathrm{~h}$. Por hipocalcemia persistente de $6 \mathrm{y}$ $7 \mathrm{mg} / \mathrm{dl}$; además del aporte endovenoso de calcio, se inició calcitriol vo $0,5 \mathrm{ug} /$ día, logrando corregir la calcemia al $5^{\circ}$ día de aporte endovenosos de calcio y calcitriol en dosis de $2 \mathrm{ug} /$ día. Una vez estabilizada la calcemia se disminuyó progresivamente el aporte de calcio intravenoso hasta su suspensión mientras se iniciaba la administración oral llegando a requerir $120 \mathrm{mg} / \mathrm{kg} /$ día de carbonato de calcio, hasta el alta.

La dosis de calcitriol y calcio se disminuyó en forma ambulatoria de acuerdo a la calcemia y a la calciuria, recibiendo actualmente a los 4 meses de seguimiento, 0,5ug de calcitriol y Vit D 400U/día. Tabla 1 muestra una síntesis de la evolución de los parámetros bioquímicos durante su tratamiento ambulatorio.

A los 6 meses de iniciado el tratamiento (2 años 10 meses), su peso 14,200 (P/E p65, $0,4 \mathrm{DS})$ y talla $85 \mathrm{~cm}$ (T/E p2,-1,89 DS), desaparecieron los signos de raquitismo activo persistiendo sólo el ensanchamiento metafisa- 
Tabla 1. Evolución bioquímica del paciente durante el tratamiento

\begin{tabular}{|c|c|c|c|c|c|}
\hline $\begin{array}{l}\text { Meses de } \\
\text { tratamiento }\end{array}$ & Diagnóstico & 1 mes & 2 mes & 3 mes & 6 meses \\
\hline $\begin{array}{l}\text { Calcio } \\
(8,5-10 \mathrm{mg} / \mathrm{dl})\end{array}$ & 5,9 & 9,2 & 10 & 10,2 & 9,3 \\
\hline $\begin{array}{l}\text { Fósforo } \\
(3,5-4,5 \mathrm{mg} / \mathrm{dl})\end{array}$ & 4,9 & 6,2 & 5,8 & 5,6 & 5 \\
\hline $\begin{array}{l}\text { Fosfatasa alcalina } \\
(<600 \mathrm{U} / \mathrm{L})\end{array}$ & 1.614 & 958 & 630 & 330 & 320 \\
\hline $\begin{array}{l}\text { Índice } \mathrm{Ca} / \mathrm{Cr} \\
(<0,2)\end{array}$ & & 0,04 & 0,06 & 0,04 & 0,06 \\
\hline $\begin{array}{l}\text { 25OH vitamina } \mathrm{D} \\
(>35)\end{array}$ & 24,7 & & & & \\
\hline Ac trasglutaminasa & $(-)$ & & & & \\
\hline Tratamiento & $\begin{array}{l}\text { Calcitriol } 2 \text { ug/día } \\
\text { Calcio } 120 \mathrm{mg} / \mathrm{kg} / \mathrm{d}\end{array}$ & $\begin{array}{l}\text { Calcitriol 1,5 ug/d } \\
\text { Calcio } 120 \mathrm{mg} / \mathrm{kg}\end{array}$ & $\begin{array}{c}\text { Calcitriol 1ug/día } \\
\text { calcio }(+)\end{array}$ & $\begin{array}{l}\text { Calcitriol 0,75 ug/d } \\
\text { Calcio } 500 \mathrm{mg} / \mathrm{día}\end{array}$ & $\begin{array}{c}\text { Calcitriol } 0,5 \mathrm{ug} / \mathrm{d} \\
\text { Vit D } 400 \mathrm{UI} / \mathrm{d}\end{array}$ \\
\hline
\end{tabular}

Índice Ca/Cr: Índice Calcio/Creatinina.

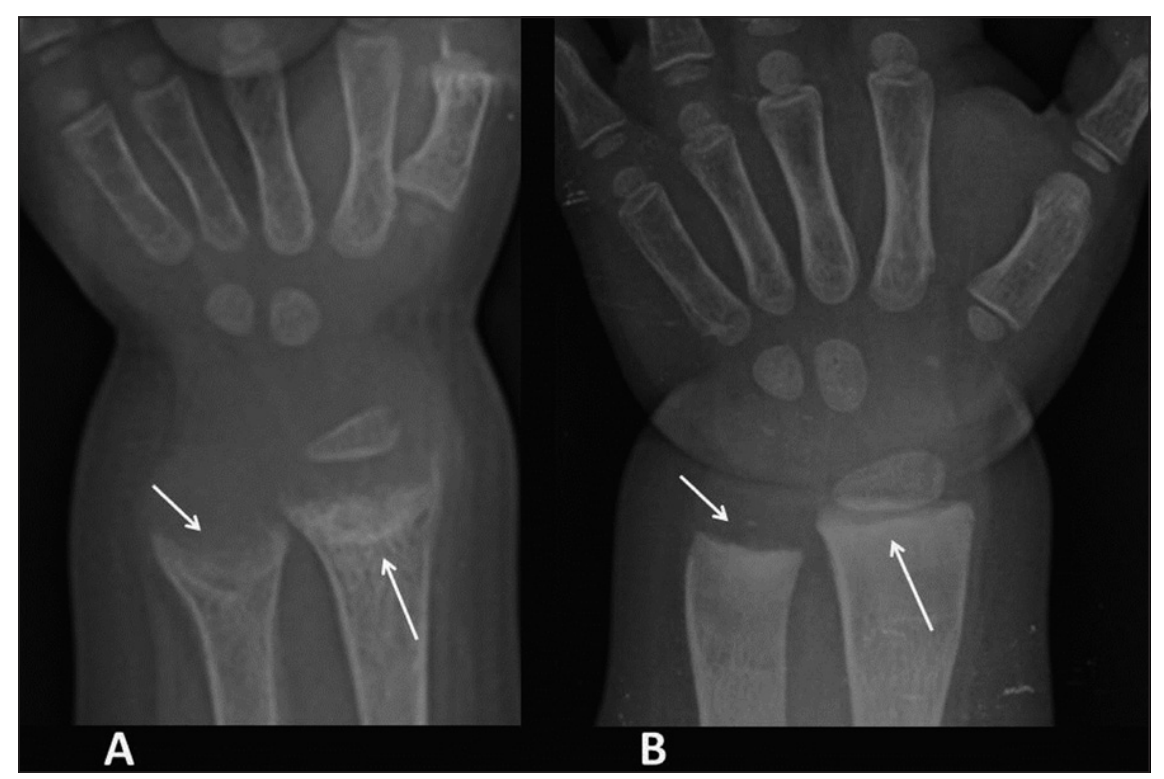

Figura 4. (A) Radiografía de muñeca muestra osteopenia difusa e irregularidad de las metáfisis distales del radio y del cúbito (flechas). (B) Radiografía de muñeca luego de tres meses de tratamiento con calcitriol muestra importante mejoría en la mineralización ósea y corrección de las alteraciones metafisiarias del radio y del cúbito (flechas). rio, la marcha si bien aún presentaba dificultad lograba desplazarse con mayor facilidad, sin caídas. A pesar del corto tiempo de evolución, las radiografías mostraban una mineralización de los huesos del carpo y del plato epifisiario con leve disminución del aspecto en copa (figura 4).

\section{Discusión}

Presentamos a una niña prescolar de 2 años y 5 meses con diagnóstico tardío de raquitismo pese a los signos asociados como retraso del crecimiento, tetania, trastorno de la marcha y deformidades óseas. 
El raquitismo se caracteriza por alteración de la mineralización de los huesos en crecimiento, las manifestaciones clínicas dependen de la severidad y de la edad de ini$\mathrm{cio}^{5,6}$.

Las alteraciones óseas son más floridas en la infancia como cráneo tabes, genu valgo o genu varo, ensanchamiento de las muñecas, rodillas y tobillos, rosario costal y surco de Harrison, otras características incluyen retardo del crecimiento, cierre tardío de la fontanela, frente prominente, irritabilidad, fracturas pato- lógicas, retardo en la dentición, debilidad muscular que produce hipotonía y retardo del desarrollo psiomotor ${ }^{3,7}$. La hipocalcemia severa puede producir temblores, debilidad muscular, tetania, espasmo carpo-pedal y laringoespasmo; también puede producir anemia y mayor susceptibilidad a adquirir infecciones respiratorias $^{5,6}$.

Nuestra paciente presentaba una caída en la curva de crecimiento a contar de los 16 meses, retardo en el inicio y alteraciones de la marcha, asociada a tetania que fueron interpretadas

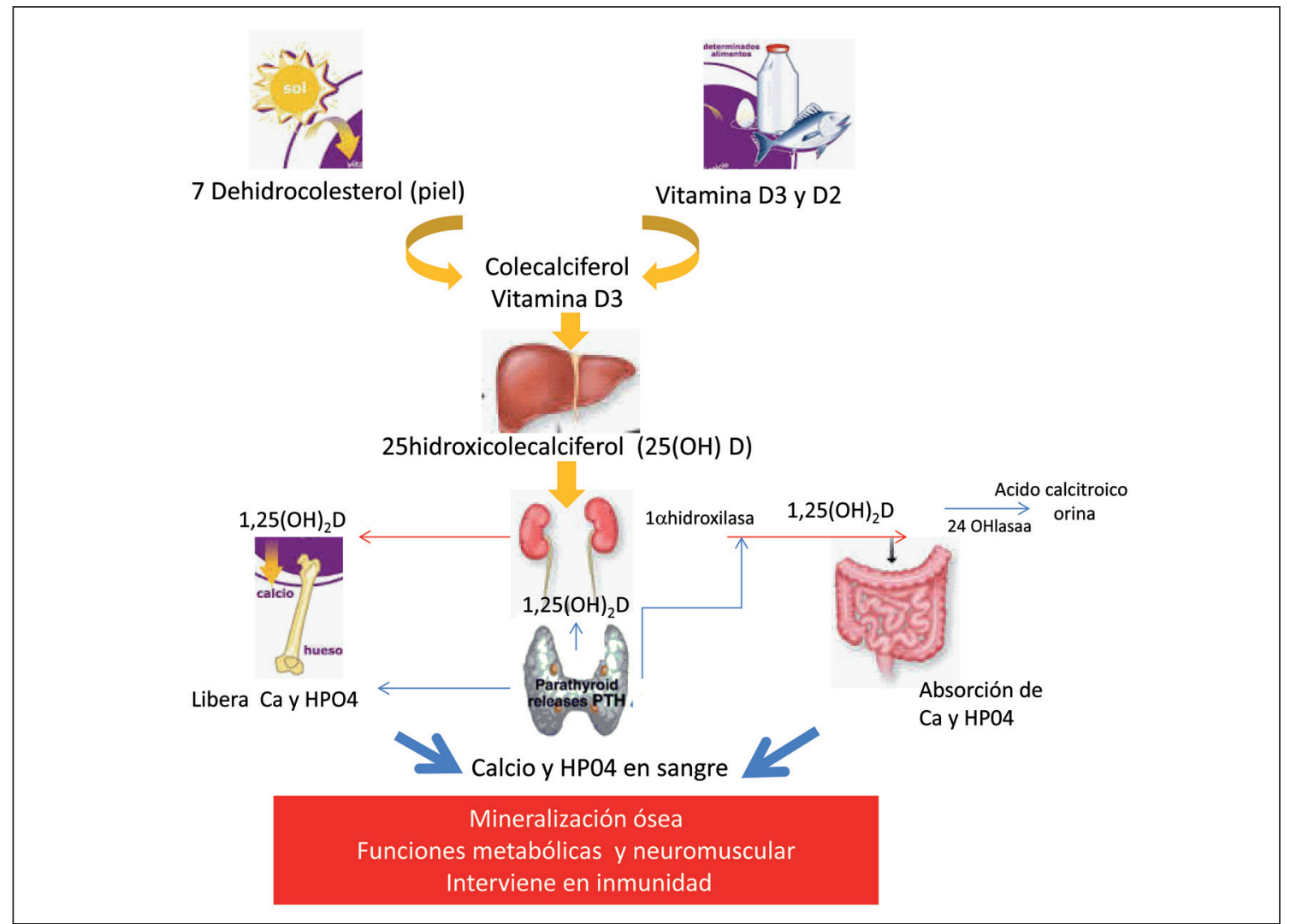

Figura 5. La fotoproducción y el metabolismo de la vitamina D y los diversos efectos biológicos de la 1,25(OH)2D sobre el calcio, el fósforo, y el metabolismo óseo. La vitamina D proveniente de la piel a través de la exposición a la radiación UVB o la dieta en forma de vitamina D2 o vitamina D3; una vez en la circulación es convertido por 25-hidroxilasa (25-OHasa) en el hígado a $25(\mathrm{OH}) \mathrm{D}$. .En los riñones gracias a la 1hidroxilasa, la $25(\mathrm{OH}) \mathrm{D}$ es hidrolizada a 1,25(OH)2D. La 1,25 (OH) 2D mejora la absorción intestinal de calcio y fósforo y estimula la expresión de RANKL en los osteoblastos que interactúan con su receptor RANK en los preosteoclastos para inducir la actividad osteoclástica madura, que libera el calcio y el fósforo (HPO4) hacia la circulación. Además, la 1,25 (OH) 2D inhibe la 1-OHasa renal y estimula la expresión de la $25(\mathrm{OH})$ D-24-hidroxilasa renal (24-OHasa). La 24-OHasa permite la destrucción de la 1,25 (OH) 2D en un ácido calcitroico metabolito inactivo soluble en agua (adaptado de Holick MF. 2006 ${ }^{4}$ ). 
como crisis parciales, además de alteraciones óseas importantes que luego fueron confirmadas con el estudio radiológico.

Una de las causas más frecuentes de raquitismo es el déficit de vitamina $\mathrm{D}$, por baja ingesta o falta de exposición solar. A partir de la revolución industrial su incidencia ha disminuido en países desarrollados; pero sigue siendo un problema de salud importante en los países en vías de desarrollo ${ }^{8,9}$. Los hijos de madres con niveles adecuados de vitamina D están protegidos durante los primeros meses de vida, ya que la vitamina $\mathrm{D}$ cruza la placenta asegurando niveles adecuados los 2 primeros meses; la lactancia materna contiene un 20$30 \%$ de la concentración plasmática materna de vitamina D2 y D3, aporte que resulta insuficiente ${ }^{10}$. Por lo tanto, si el estatus materno de vitamina $\mathrm{D}$ es pobre y la lactante mantiene lactancia materna exclusiva, la vitamina $D$ se hace deficitaria, dando lugar al raquitismo carencial ${ }^{11}$.

La activación de la vitamina D3 en la piel depende de la exposición solar (Figura 5) ${ }^{4}$, por lo que la insuficiente exposición solar es una causa común de raquitismo en especial en invierno, pieles oscuras y excesivo uso de bloqueadores solares ${ }^{4}$. Factores como aumento de la migración, alimentación inadecuada y baja exposición solar, en los últimos años han determinado un resurgimiento a nivel mundial del raquitismo carencial ${ }^{9,12}$.

En Chile el raquitismo carencial prácticamente ha desaparecido, debido al aporte regular de esta vitamina a los niños con lactancia materna exclusiva. En nuestro país los alimentos no se suplementan con vitamina D como en los países del norte de América o de Europa, pues en la mayor parte del territorio la radiación solar se considera suficiente para suplir los requerimientos ${ }^{13,14}$. En nuestra paciente la ingesta de vitamina $D$ fue insuficiente durante el primer año de vida, lo que podría orientar a una deficiencia de vitamina $\mathrm{D}$, sin embargo los niveles normales de $25 \mathrm{OH}$ vitamina $\mathrm{D}$, la ausencia de síntomas digestivos, sin otras carencias nutricionales, los anticuerpos antitransglutaminasa, $\operatorname{IgA}$, función hepática y renal normal y la difícil corrección de la calcemia, nos orientaba hacia otro tipo de raquitismo.

Dentro de las otras causas de raquitismo, un primer grupo está constituido por los hiposfosfémicos, y el segundo por los pseudodeficientes o vitamina $\mathrm{D}$ dependientes tipo I y II. La clínica y la radiología en los diferentes tipos de raquitismo pueden ser similares, pero los exámenes de laboratorio son la piedra angular para diferenciar los distintos trastornos ${ }^{15}$.

El raquitismo hipofosfémico familiar consiste en un defecto genético autosómico dominante o ligado al $\mathrm{X}$ en el trasporte tubular proximal de fosfato y de la 1 alfa hidroxilación renal de la vitamina $\mathrm{D}$, por alteración en el factor fosfatúrico FGF23 ${ }^{16,17}$.

Se evidencia a partir de los 6-10 meses de edad, cursa con fosfemia baja, fosfaturia elevada, fosfatasa alcalina alta, calcio y niveles de PTH normales ${ }^{18}$. El síndrome de Fanconi de causa genética o adquirida produce hipofosfemia por pérdida renal de fosfato acompañado de glucosuria y aminoaciduria ${ }^{6}$. El fósforo normal y la hipocalcemia severa asociada a PTH elevada en nuestra paciente, descartó la posibilidad de raquitismo hipofosfémico.

En el segundo grupo de raquitismos vitamina $\mathrm{D}$ resistente la presentación clínica es la de un raquitismo con alteraciones óseas, en presencia de hipocalcemia grave, hiperparatiroidismo secundario, fosfatasa alcalina elevada y normofosfemia; sin embargo en algunos casos el fósforo plasmático puede estar disminuido por acción fosfatúrica de la PTH. Este perfil hormonal puede hallarse en cualquiera de las tres formas de raquitismo resistente a vitamina D: defecto de la 25 hidroxilasa, raquitismo vitamina D dependiente tipo I y II.

El defecto de la 25 hidroxilasa es la forma más rara de las tres, se descartó en la paciente porque la $25 \mathrm{OH}$ Vitamina D estaba normal. El raquitismo vitamina $\mathrm{D}$ dependiente tipo I es un raro defecto genético autosómico recesivo, en donde los individuos afectados tienen raquitismo, hipocalcemia, hiperparatiroidismo y disminución en los niveles séricos de $1,25(\mathrm{OH})_{2}$ Dihidroxi Vitamina D con niveles normales de $25 \mathrm{OH}$ Vitamina D. Resulta de una mutación inactivante del gen que codifica 
para citocromo P450, componente de la enzima 1 alfa hidroxilasa localizado en el cromosoma 12p13.1-13.3 y permite la hidroxilación del calcidiol (25 OH Vit D) en calcitriol $\left(1,25(\mathrm{OH})_{2} \mathrm{D}\right)$ a nivel renal. Estos niños responde a la administración oral de la forma activa de vitamina $\mathrm{D}$ calcitriol $^{19}$.

El raquitismo Vitamina D dependiente tipo II se debe a un defecto autosómico recesivo a nivel del receptor de vitamina D (VDR), la mayoría de los pacientes presentan raquitismo, asociado a alopecia y niveles más bien altos $\mathrm{de}\left(1,25(\mathrm{OH})_{2} \mathrm{D}\right)$, algunos paciente que responden con dosis más altas de calcitriol mientras que otros no.

Otra forma de raquitismo resistente conocida como tipo III, se debe a la expresión anormal de la proteína ligadora de receptor VDR (HRBP) impidiendo así la formación del complejo $\left(1,25(\mathrm{OH})_{2} \mathrm{D}-\mathrm{VDR}-\mathrm{RXR}\right.$, siendo los paciente con esta forma totalmente resistente al tratamiento con calcitriol ${ }^{19}$.

El diagnóstico diferencial entre estas tres formas se realiza a través de la medición de calcitriol $\left(1,25(\mathrm{OH})_{2} \mathrm{D}\right)$; dado que no contamos en Chile con la medición de ésta, en nuestra paciente la buena respuesta a la administración exógena de calcitriol $\left(1,25(\mathrm{OH})_{2} \mathrm{D}\right)$ y el proceso de curación clínico y radiológico, hace planteable la forma de raquitismo resistente tipo I (RVDDI) ${ }^{19}$.

\section{Conclusión}

El raquitismo no es una enfermedad del pasado, por el contrario, es una patología que cada vez se hace más prevalente, que debemos considerar dentro del diagnóstico diferencial de todo niño que presente mal crecimiento, retardo del desarrollo psicomotor y anormalidades esqueléticas características en el estudio radiológico. Si bien generalmente puede presentarse como un trastorno crónico de la mineralización ósea, también puede cursar con sintomatología aguda debida a hipocalcemia, manifestándose como convulsiones, tetania o laringoespasmo, no exentos de riesgo vital.
Un mejor conocimiento de esta enfermedad permitirá evitar el retraso en el diagnóstico y un tratamiento más oportuno.

\section{Referencias}

1.- Aranguiz C, Trujillo O: Emergencias endocrinas en pediatría: diagnóstico y manejo. Rev Med Chile 2005; 133: 1371-80.

2.- Inzucchi SE: V I Disease of calcium metabolism and metabolic bone disease In: Endocrinology:VI Calcium Metabolism and Metabolic Bone Disease; 2003. p. 1-14.

3.- Nield LS, Mahajan P, Joshi A, Kamat D: Rickets: not a disease of the past. Am Fam Physician 2006; 74 (4): 619-26.

4.- Holick MF: Resurrection of vitamin D deficiency and rickets. J Clin Invest 2006; 116 (8): 2062-72.

5.- Wharton B, Bishop N: Rickets. Lancet 2003; 362 (9393): 1389-400.

6.- Mughal Z: Rickets in childhood. Semin Musculoskelet Radiol 2002; 6 (3): 183-90.

7.- Shore RM, Chesney $R W$ : Rickets: Part I. Pediatr Radiol 43 (2): 140-51.

8.- Prentice A: Nutritional rickets around the world. J Steroid Biochem Mol Biol 136: 201-6.

9.- Wagner $C$ : Rickets: emerging from obscurity. Am Fam Physician 2006; 74 (4): 561-2.

10.- Dawodu A, Tsang RC: Maternal vitamin D status: effect on milk vitamin $\mathrm{D}$ content and vitamin $\mathrm{D}$ status of breastfeeding infants. Adv Nutr 3 (3): 353-61.

11.- Wagner CL, Greer FR: Prevention of rickets and vitamin D deficiency in infants, children, and adolescents. Pediatrics 2008; 122 (5): 1142-52.

12.- Fischer PR, Thacher TD, Pettifor JM: Pediatric vitamin $\mathrm{D}$ and calcium nutrition in developing countries. Rev Endocr Metab Disord 2008; 9 (3): 181-92.

13.- Aguirre C, Depix MS, Pumarino H: Determinación de los niveles séricos de 25-hidroxivitamina D y sus variaciones estacionales en una población normal joven. Rev Med Chile 1996; 124 (6): 675-9.

14.- Reyes ML, Hernández MI, Palisson F, Talesnik E: Deficiencia de vitamina D en niños con enfermedades crónicas evaluados por osteopenia. Rev Med Chile 2002; 130 (6): 645-50.

15.- Shore RM, Chesney RW: Rickets: Part II. Pediatr Radiol 43 (2): 152-72.

16.- DiMeglio LA, Econs MJ: Hypophosphatemic rickets. Rev Endocr Metab Dis 2001; 2 (2): 165-73. 
17.- Ramon I, Kleynen P, Body JJ, Karmali R: Fibroblast growth factor 23 and its role in phosphate homeostasis. Eur J of Endocrinol 2010; 162: 1-10.

18.- Hee Y, Cho Bum H, Lee Ju H, Kang Il S, Ha Hae I, Cheong, Yong Choi: A Clinical and Molecular Genetic
Study of Hypophosphatemic Rickets in Children. Pediatr Res 2005; 58 (2): 329-33.

19.- Kato S, Yoshizazawa T, Kitanaka S, Murayama A, Takeyama K: Molecular genetics of vitamin D-dependent hereditary rickets. Horm Res 2002; 57 (3-4): 73-8. 